\title{
Combined genotoxicity of chlorinated products from tyrosine and benzophenone-4
}

\author{
Yangyang Chang ${ }^{\mathrm{a}, \mathrm{d}}$, Yaohui Bai ${ }^{\mathrm{a}}$, Qinghua Ji ${ }^{\mathrm{a}, \mathrm{d}}$, Yang Huo ${ }^{\mathrm{a}, \mathrm{d}}$, Huijuan Liu ${ }^{\mathrm{b}}$, \\ John C. Crittenden ${ }^{c, *}$, Jiuhui $\mathbf{Q u}^{\mathrm{a}, *}$ \\ a Key Laboratory of Drinking Water Science and Technology, Research Center for Eco-Environmental Sciences, Chinese Academy of Sciences, Beijing 100085, \\ China \\ b State Key Laboratory of Environmental Aquatic Chemistry, Research Center for Eco-Environmental Sciences, Chinese Academy of Sciences, Beijing 100085, \\ China \\ ${ }^{\mathrm{c}}$ Brook Byers Institute for Sustainable Systems and School of Civil and Environmental Engineering, Georgia Institute of Technology, 828 West Peachtree \\ Street, Atlanta, GA 30332, United States \\ d University of Chinese Academy of Sciences, Beijing 100049, China
}

\section{H I G H L I G H T S}

- Genotoxicity of chlorinated mixture (GCM) is not predicted by that of single (GCI).

- $\mathrm{pH}$ is an important factor affecting difference between GCM and GCI $\left(\mathrm{G}_{\Delta}=\mathrm{GCM}-\mathrm{GCI}\right)$.

- $\mathrm{G}_{\Delta}>0$ occurred at pH 5.0-6.1 and $\mathrm{G}_{\Delta}<0$ occurred at pH 6.3-8.0.

- $\mathrm{G}_{\Delta}$ is determined by N-DBPs decrease in mixture and combined effects between DBPs.

- TON ratio can be used to estimate the $\mathrm{G}_{\Delta}$ value.

\section{A R T I C L E I N F O}

\section{Article history:}

Received 15 June 2016

Received in revised form

21 September 2016

Accepted 8 October 2016

Available online 11 October 2016

\section{Keywords:}

Genotoxicity

Combined effects

N-DBPs

Chlorination

sos/umu test

\section{G R A P H I C A L A B S T R A C T}

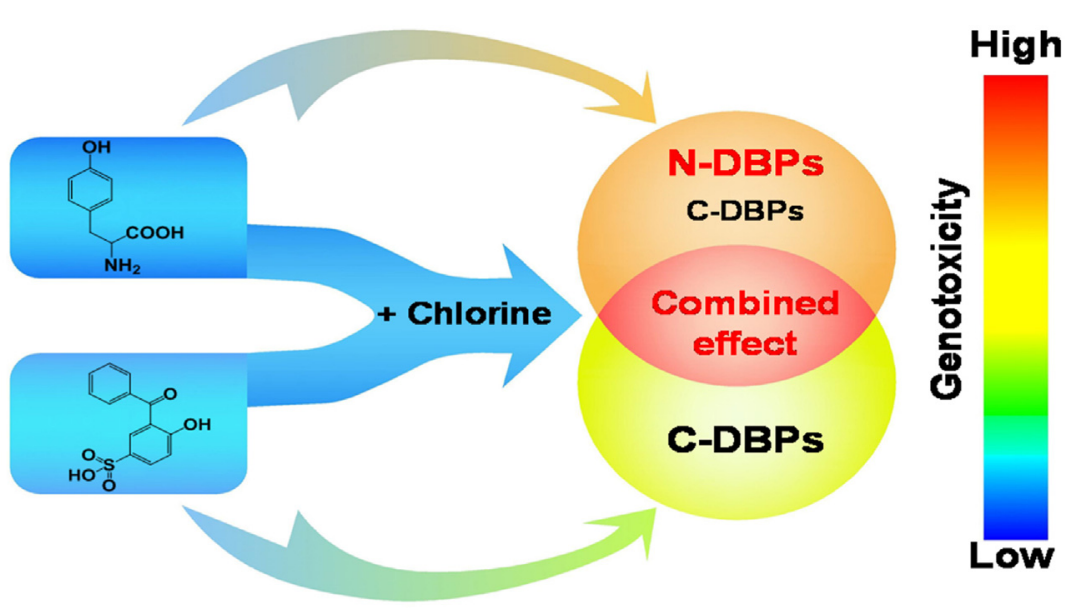




\section{Introduction}

Chlorine is one of the most commonly used disinfectants in drinking water. However, disinfection by-products (DBPs, Acronyms used in this paper is listed in Box 1) with genotoxic, mutagenic and carcinogenic activities are produced during chlorination. In fact, chlorine reacts with natural organic matter (e.g., humic/fulvic acids, proteins and amino acids) [1-3], anthropogenic chemicals (e.g., pesticides and personal care products) [4], and salts (e.g., bromide and iodide) [5], and produces a wide variety of DBPs [6]. Although most DBPs' concentrations are very low $(\sim 1-100 \mu \mathrm{g} / \mathrm{L})$ [7], they may pose a human health hazard as a result of persistent exposure and/or their synergistic effects [8-10]. Many previous studies have focused on the toxicity of a single DBP [2], a single chlorinated compound [11-13] or chlorinated water samples [14-16]. However, when multiple precursors are chlorinated, little is known about the factors that cause the toxicity of the mixture and whether the mixture's toxicity can be estimated from the sum of the toxicities of the individual chlorinated precursors. Accordingly, we need to determine how and why the toxicity varies during chlorination of multiple precursors.

The composition of source water is complicated. Thus it is difficult to study the underlying mechanism of combined genotoxicity of DBPs from multiple precursors. To simplify the study, we selected two representative precursors, tyrosine (Tyr, a natural organic matter) and benzophenone-4 (BP-4, an anthropogenic chemical). Tyr is a naturally occurring amino acid and is present in many peptides, proteins, and algae $[17,18]$. The largest influent concentration of the hydrolysable Tyr is $27.4 \mu \mathrm{g} / \mathrm{L}$ [19]. Its DBPs were identified and quantified in previous studies [20-23]. BP-4 is one of the most widely used UV sunscreens and is used in a variety of personal care products (e.g., sunscreens, lipsticks, lotions, shampoos and cosmetics) [24-26]. BP-4 has been detected in wastewater, river water, and sea water, at concentrations ranging from ng/L to high $\mu \mathrm{g} / \mathrm{L}$ levels $[27,28]$. However, traditional wastewater treatment plants did not efficiently eliminate BP-4. Moreover, BP-4 could be present in reclaimed water. Consequently, it is important to determine BP4 byproducts that are formed during chlorination [13]. Both Tyr and BP-4 are common precursors in reclaimed source waters. Furthermore, Tyr is a precursor of nitrogen disinfection by-products (N-DBPs) [20], and BP-4 reacts with disinfectants only to form carbonaceous by-products (C-DBPs) [13]. In vivo genotoxicity and cytotoxicity assays suggest that the genotoxic and cytotoxic activities of N-DBPs are higher than those of C-DBPs [29-31]. Accordingly, curiosity in the study of N-DBPs has increased rapidly.
Accordingly, we hypothesized that after chlorination, the toxicity of a Tyr and BP-4 mixture could not be equal to the sum of individual toxicities that result from chlorinating them separately. In this study, we used genotoxicity to test this hypothesis and then explore: (i) what is the main experimental condition affecting the difference between the genotoxicity of the chlorinated mixture (GCM) and the sum of genotoxicities of the individual chlorinated compounds (GCI), (ii) what is the underlying mechanism of the genotoxicity difference between GCM and GCI $\left(G_{\Delta}\right.$, $\mathrm{G}_{\Delta}=\mathrm{GCM}-\mathrm{GCI}$ ), (iii) develop a methodology to estimate $\mathrm{G}_{\Delta}$.

\section{Materials and methods}

\subsection{Chemicals and solution preparation}

Standards for the analysis of the following DBPs were purchased from AccuStandard (USA): (1) chloroform (CF) and (2) halogenated volatile organic chemical as a mixture of DBPs including dichloroacetonitrile (DCAN), trichloroacetonitrile (TCAN), chloral hydrate (CH), chloropicrin (CP), 1,1-dichloropropanone (DCP) and 1,1,1-trichloro-2-propanone (TCP). Two species of haloacetic acids (HAAs, including dichloroacetic acid (DCAA) and trichloroacetic acid (TCAA)) were purchased from Bei Na Chuang Lian Ltd. (China). Dichloroacetamide (DcAcAm) and trichloroacetamide (TcAcAm) were purchased from Alfa Aesar (Germany) and J\&K (China), respectively. Ethyl acetate and methyl tert-butyl ether (MTBE) used to extract DBPs were obtained from Fisher (USA). Tyr was obtained from Sigma-Aldrich (USA). BP-4 and phloretic acid (PA) were obtained from J\&K (China). The chemical structures of Tyr, BP-4 and PA were listed in Fig. 1. The sodium hypochlorite aqueous solution was obtained from Sinopharm Chemical Reagent Co., Ltd (China). The concentration of the chlorine stock solution was determined using the $N, N$-diethyl- $p$-phenylenediamine ferrous titration method. All chemicals were of analytical grade and used without further purification. All reagent solutions were prepared with ultrapure water (resistivity $18.2 \mathrm{M} \Omega \mathrm{cm}$, Millipore, US). Additionally, all bottles were rinsed three times with ultrapure water and then dried in a muffle furnace at $500^{\circ} \mathrm{C}$ for $4 \mathrm{~h}$.

\subsection{Chlorination experiments}

Chlorination experiments were performed under headspacefree conditions in glass screw-cap vials that were capped with Teflon-faced septa and kept in the dark. Hydrochloric acid and sodium hydroxide were used to adjust the $\mathrm{pH}(\mathrm{pH}=5.0-8.0) .50 \mathrm{mM}$

\begin{tabular}{|c|c|c|c|}
\hline DBPs & Disinfection by-products & TCP & 1,1,1-trichloro-2-propanone \\
\hline Tyr & tyrosine & HAAs & haloacetic acids \\
\hline BP-4 & Benzophenone-4 & DCAA & dichloroacetic acid \\
\hline GCM & genotoxicity of chlorinated mixture & TCAA & trichloroacetic acid \\
\hline $\mathrm{GCl}$ & $\begin{array}{l}\text { the sum of genotoxicity of chlorinated } \\
\text { individual precursor }\end{array}$ & DcAcAm & Dichloroacetamide \\
\hline $\mathrm{G}_{\Delta}$ & $\begin{array}{l}\text { the difference between genotoxicity of } \\
\text { chlorinated mixture and the sum of } \\
\text { genotoxicity from chlorinated } \\
\text { individual precursor }\end{array}$ & TcAcAm & trichloroacetamide \\
\hline TON & total organic nitrogen & MTBE & methyl tert-butyl ether \\
\hline $\mathrm{N}-\mathrm{DBPs}$ & nitrogen-containing DBPs & $\mathrm{Cl}_{2}$ & chlorine \\
\hline C-DBPs & carbonaceous by-products & PA & phloretic acid \\
\hline $\mathrm{CF}$ & chloroform & GC/MS & gas chromatography/mass spectrometry \\
\hline DCAN & dichloroacetonitrile & UPLC/DAD & ultra-performance liquid chromatography/diode array detector \\
\hline TCAN & dichloroacetonitrile & Q-TOF-MS & Quadrupole-Time of Flight Mass Spectrometer \\
\hline $\mathrm{CH}$ & chloral hydrate & TKN & Total Kjeldahl nitrogen \\
\hline $\mathrm{CP}$ & chloropicrin & $\mathrm{TEQ}_{4-\mathrm{NOO}}$ & Toxicity Equivalent Quotient \\
\hline DCP & 1,1-dichloropropanone & $\mathrm{HOCl}$ & hypochloric acid \\
\hline SD & Supplementary data & & \\
\hline
\end{tabular}


<smiles>COc1cc(O)c(C(=O)c2ccccc2)cc1S(=O)(=O)O</smiles>

Exact Mass: 308.04<smiles>NC(Cc1ccc(O)cc1)C(=O)O</smiles>

Exact Mass: 181.07<smiles>O=C(O)CCc1ccc(O)cc1</smiles>

Exact Mass: 166.06

BP-4 (4065-45-6)

Tyrosine (60-18-4)

phloretic acid (501-97-3)

Fig. 1. Chemical structures of the tested compounds.

of phosphate buffer solution was applied to maintain the desired $\mathrm{pH}$ levels for $\mathrm{pH}$ values of 6.0 to 8.0 , and $100 \mathrm{mM}$ phosphate buffer solution was used to adjust the desired $\mathrm{pH}$ level at $\mathrm{pH}=5.0$. To easily determine the concentrations and genotoxicity of chlorination byproducts from Tyr and BP-4, the initial concentrations of precursors were designed as $0.1 \mathrm{mM}$ in the experiments. The experiments were conducted in five phases. For phase 1, to ensure excess chlorine during chlorination, $3 \mathrm{mM}$ solution of free chlorine $\left(\mathrm{Cl}_{2}\right)$ was added to $200 \mathrm{~mL}$ solutions of Tyr $(0.1 \mathrm{mM}), \mathrm{BP}-4(0.1 \mathrm{mM})$ and a mixture $(0.1 \mathrm{mM}$ of Tyr and $0.1 \mathrm{mM}$ of BP-4) (Fig. S1(a), Supplementary data (SD)). (These results allowed us to determine whether the GCM varies relative to GCI and the primary environmental factors affecting $G_{\Delta}$.) For phase 2, there was a measurable chlorine residual after $72 \mathrm{~h}$ of chlorination when the initial molar concentration of chlorine $\left(\left[\mathrm{Cl}_{2}\right]_{0}\right)$ was 15 times as much as that of precursors $\left([\mathrm{Tyr}]_{0},[\mathrm{BP}-4]_{0}\right.$ and $[\text { mixture }]_{0}$ ) (Fig. S1(b), SD). To confirm at which time the $\mathrm{G}_{\Delta}$ is the largest, varying reaction time experiments were conducted. Reaction times were $10 \mathrm{~min}, 1 \mathrm{~h}, 6 \mathrm{~h}, 24 \mathrm{~h}$ and $72 \mathrm{~h}$. For total mixture concentrations of $0.1 \mathrm{mM}$, these molar ratios of $[\mathrm{Tyr}]_{0}:[\mathrm{BP}-4]_{0}$ were chlorinated using $1.5 \mathrm{mM}$ of free chlorine at room temperature $\left(25 \pm 0.2^{\circ} \mathrm{C}\right): 0: 1,2: 8,5: 5,8: 2$ and $1: 0$. (These results allowed us to determine which molar ratio yields the largest $\mathrm{G}_{\Delta}>0$.) For phase 3 , Tyr, BP-4 and a mixture of the two ([Tyr $]_{0}$ :[BP$4]_{0}=8: 2$, which corresponded to a mixture investigated in phase 2 ) were chlorinated for several narrow $\mathrm{pH}$ intervals at room temperature $\left(25 \pm 0.2^{\circ} \mathrm{C}\right)$. (These results allowed us to determine the impact of $\mathrm{pH}_{\text {on }} \mathrm{G}_{\Delta}$.) For phase 4 , Tyr with and without ammonium chloride $\left(\mathrm{NH}_{4} \mathrm{Cl}\right)$, and PA-BP-4 mixtures $\left(0.1 \mathrm{mM},[\mathrm{PA}]_{0}:[\mathrm{BP}-4]_{0}=2: 8\right.$, $5: 5,8: 2$ and $1: 0)$ were chlorinated at $\mathrm{pH}=6.0$ at room temperature $\left(25 \pm 0.2^{\circ} \mathrm{C}\right)$, respectively. (These results allowed us to determine the primary DBPs affecting GCM and GCI.) For phase $5,0.08 \mathrm{mM}$ of Tyr and $0.02 \mathrm{mM}$ of BP-4 were chlorinated separately. The postchlorination samples were mixed (hereafter we referred to them as the post-chlorination mixture), followed by genotoxicity determination. (These results allowed us to determine the combined effects.) To completely quench the chlorine residual, ascorbic acid was used, and the dosage was double the initial molar concentration of chlorine. All experiments were conducted in triplicate.

\subsection{Identification of transformation products}

The reaction byproducts of Tyr were analyzed using gas chromatography/mass spectrometry (GC/MS, Agilent, USA) with an electron impact source (Agilent, USA) [32]. The transformation products of $\mathrm{BP}-4$ were analyzed by a Waters ultra-performance liquid chromatography/diode array detector (UPLC/DAD) system equipped with a Quadrupole-Time of Flight Mass Spectrometer (QTOF-MS) (USA) [13]. The experimental methods are presented in Text S1.

\subsection{DBP analysis}

$\mathrm{CF}, \mathrm{CH}, \mathrm{CP}, \mathrm{DCP}, \mathrm{TCP}, \mathrm{DCAN}$ and TCAN were extracted using MTBE and analyzed by USEPA's method 551.1 [33]. Two species of HAAs, including DCAA and TCAA, were methylated using acidic methanol, followed by extraction using MTBE, and measured using USEPA method 552.3 [34]. DcAcAm and TcAcAm were analyzed by GC/MS [23]. More analysis details are described in Text S2.

\subsection{Determination of total organic nitrogen (TON)}

Concentrations of TON were estimated by subtracting the ammonia nitrogen $\left(\mathrm{NH}_{3}-\mathrm{N}\right)$ concentration from the total Kjeldahl nitrogen (TKN) concentration. The TKN concentrations were determined by the modified nitrogen method [35] using a Digestion Unit K-435 and AutoKjeldahl Unit K-370 (China). Concentrations of $\mathrm{NH}_{3}-\mathrm{N}$ were measured by the Nessler's reagent colorimetric method [36] using a U-3010 UV-vis spectrophotometer (Hitachi Co, Japan) equipped with $10 \mathrm{~mm}$ quartz cuvettes. More experimental details were listed in Text S3 of SD

\subsection{Genotoxicity test}

To evaluate the genotoxic responses to Tyr, BP-4 and their mixture with and without chlorination, a modified SOS/umu test [37] using Salmonella typhimurium TA1535/pSK1002 without S9 activation was used. The SOS/umu assay has been shown to be useful as a biological endpoint for genotoxicity monitoring of DBPs containing unknown genotoxic substances [12,38,39]. Prior to genotoxicity measurement, the samples were concentrated using two pre-conditioned Oasis HLB solid extraction cartridges $(6 \mathrm{~mL}$ $500 \mathrm{mg}$, Waters, USA). The extracts were then dissolved into $200 \mu \mathrm{L}$ of dimethyl sulfoxide. The genotoxic activities of samples were qualitatively and quantitatively expressed by the induction factor and the equivalent 4-nitro-1-oxide (4-NQO) concentration (Toxicity Equivalent Quotient, $\mathrm{TEQ}_{4-\mathrm{NQO}}$ ), respectively. In genotoxicity tests, all samples were evaluated in triplicate. The experimental procedure is described in Text S4.

\subsection{Statistical analysis}

The Pearson correlation coefficient was determined using SPSS 19.0 (IBM) and the relationships between GCM and the concentrations of DBPs were determined. The independent sample T-test was carried out to determine if GCM and the genotoxicity of the post chlorination mixture were significantly different from GCI. The T-test was also used to determine if there were any significant genotoxicity differences for chlorinated Tyr with $\mathrm{NH}_{4} \mathrm{Cl}$ compared to chlorinated Tyr alone, as well as for the chlorinated Tyr and BP-4 mixtures $\left([\mathrm{Tyr}]_{0}:[\mathrm{BP}-4]_{0}=2: 8,5: 5,8: 2\right.$ and $\left.1: 0\right)$ compared to chlori- 


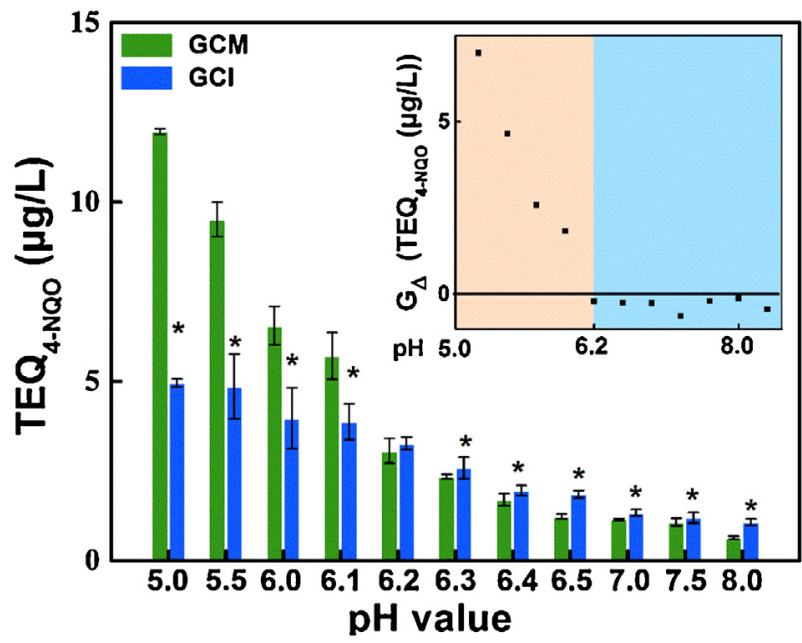

Fig. 2. The variation of GCM and GCI at $\mathrm{pH} 5.0-8.0$ after 24-h chlorination $\left([\mathrm{Tyr}]_{0}:[\mathrm{BP}-4]_{0}=8: 2, \mathrm{~T}=25^{\circ} \mathrm{C},\left[\mathrm{Cl}_{2}\right]_{0}=1.5 \mathrm{mM}\right.$ ). Inset shows $\mathrm{G}_{\Delta}$ at $\mathrm{pH} 5.0-8.0$. Asterisks indicate that GCM is significantly different from GCI $(p<0.05)$. Error bars represent the standard deviation of replicate measurements $(n=3)$.

nated PA and BP-4 mixtures ([PA $]_{0}:[\mathrm{BP}-4]_{0}=2: 8,5: 5,8: 2$ and $\left.1: 0\right)$. A non-linear regression analysis was used to determine the relationship between $G_{\Delta}$ and TON ratio. Statistical significance was accepted at $p<0.05$.

\section{Results and discussion}

\subsection{Occurrence of $G_{\Delta}$}

We found that both Tyr and BP-4 alone or as a mixture did not exhibit genotoxicity (Fig. S2). After chlorination, we observed genotoxic responses (Fig. S3), due to the formation of genotoxic byproducts $[13,40]$. Furthermore, we found that GCM was not equal to $\mathrm{GCI} . \mathrm{G}_{\Delta}$ varied with reaction $\mathrm{pH}$, time, temperature and chlorine dosage. It was observed that GCM was significantly higher than GCI at $\mathrm{pH}=6.0$. Hence, it was great significant to study the effect of $\mathrm{pH}$ on $\mathrm{G}_{\Delta}$.

\subsection{The influence of $p H$ on $G_{\Delta}$}

To further investigate the influence of $\mathrm{pH}$, we conducted experiments with different molar ratios of Tyr and BP-4 and determined the $G_{\Delta}$ values (Text S5). We found that a Tyr-to-BP-4 molar ratio of 8:2 (Fig. S4) had the largest $G_{\Delta}$; consequently, we conducted additional research on this molar ratio.

For $\mathrm{pH}$ values from 5.0 to 8.0 , the maximum $\mathrm{G}_{\Delta}$ occurred at $24 \mathrm{~h}$. (Fig. S5, SD). Accordingly, we examined the $\mathrm{G}_{\Delta}$ in a narrow $\mathrm{pH}$ interval after $24 \mathrm{~h}$ of chlorination. A significant decrease in $\mathrm{G}_{\Delta}$ was observed with increasing $\mathrm{pH}$ from 5.0 to 8.0 (Fig. 2, inset). $\mathrm{G}_{\Delta}>0$ occurred at $\mathrm{pH}$ values $5.0-6.1$, while $\mathrm{G}_{\Delta}$ was less than 0 at $\mathrm{pH}$ 6.3-8.0. Additionally, GCM and GCI decreased with increasing $\mathrm{pH}$ (Fig. 2). This can be explained by the impact of $\mathrm{pH}$ on the species distribution of hypochloric acid $(\mathrm{HOCl})$ and hypochlorite $\left(\mathrm{OCl}^{-}\right)$and the reactivity of chlorine. In acidic conditions, $\mathrm{HOCl}$ is the dominant oxidant species $\left(\mathrm{pK}_{\mathrm{a}}=7.54\right)$, and $\mathrm{HOCl}$ will open the ring of a substituted benzene. Ring opening increases the formation of DBPs that are thought to be more genotoxic [2].

\subsection{The underlying mechanism of $G_{\Delta}$}

Based on GC/MS and UPLC/MS methods, the chlorinated products of Tyr and BP-4 alone and their mixture ([Tyr $\left.]_{0}:[\mathrm{BP}-4]_{0}=8: 2\right)$ were measured at pH 6.0 (Fig. S6, SD). The species of the byproducts that were formed by Tyr and BP-4 when they were chlorinated individually were the same as those in their mixture ([Tyr $]_{0}:[\mathrm{BP}-$ $4]_{0}=8: 2$ ). This revealed that the reaction pathway of Tyr and BP-4 in mixture was basically identical to that for the individual precursors. To explore the underlying mechanism of $\mathrm{G}_{\Delta}$, it was crucial to determine the dominant DBPs affecting GCM and GCI and determine their combined effects.

\subsubsection{Dominant DBPs affecting the GCM and GCI}

To determine the primary DBPs that contribute to the genotoxicity, the possible C- and N-DBPs were measured (Fig. S7) [20]. We found that the four C-DBPs, including CF, CH, DCAA and TCAA, were not correlated $(p>0.05)$ with GCM and GCI. This suggested C-DBPs make a small contribution to GCM and GCI. However, both DCAN and TcAcAm were correlated with GCM Fig. S8 (a), (DCAN $\left(\mathrm{R}^{2}=0.411, p<0.05\right)$, TcAcAm $\left.\left(\mathrm{R}^{2}=0.701, p<0.01\right)\right)$ as well as with GCI Fig. S8 (b), (DCAN $\left(R^{2}=0.621, p<0.01\right)$, TcAcAm $\left(R^{2}=0.630\right.$, $p<0.01)$ ). The DCAN and TcAcAm genotoxicity $\left(\right.$ TEQ $_{4-N Q O}$ value: $1.7 \times 10^{-4} \mu \mathrm{g} / \mathrm{L}$ and $2.5 \times 10^{-4} \mu \mathrm{g} / \mathrm{L}$, respectively) accounted for a tiny fraction of N-DBP genotoxicity. To investigate the role of unknown N-DBPs in GCM and GCI, we compared the genotoxicity of Tyr with $\mathrm{NH}_{4}{ }^{+}$and that without $\mathrm{NH}_{4}{ }^{+}$(Fig. 3(a)), as well as the genotoxicity of Tyr and that of PA he same structure with Tyr no amine group (Fig. 3(b) and (c)) (Text S6). Results suggested that N-DBPs dominated GCM and GCI. Because $\mathrm{G}_{\Delta}$ reflected the genotoxicity difference between $\mathrm{GCM}$ and $\mathrm{GCI}, \mathrm{G}_{\Delta}$ was related to the $\mathrm{N}$-DBP production in the mixture as compared to the sum of the individual chlorinated precursors.

\subsubsection{Combined effects between DBPs of Tyr and BP-4}

The chlorination products of Tyr and BP-4 may interact to produce a synergistic or antagonistic impact on $\mathrm{G}_{\Delta}$. To investigate this, we determined the genotoxicity of the post-chlorination mixture and compared it with the GCI. We found that the post-chlorination mixture had a significantly higher genotoxicity for $\mathrm{pH}$ values from 5.0 to 7.0 and a lower genotoxicity at $\mathrm{pH} 8.0$ than the $24-\mathrm{h} \mathrm{GCI}$ (Fig. 4). This suggested that the combined effects occur between the chlorinated products of Tyr and BP-4, and they played an important determining role in the resulting $\mathrm{G}_{\Delta}$. Accordingly, $\mathrm{G}_{\Delta}$ depends on not only N-DBP production between the mixture and individual precursors but also the combined effects between DBPs from Tyr and BP-4.

\subsubsection{The role of $N$-DBPs and combined effects in $G_{\Delta}$}

To evaluate the importance of N-DBP production and the impacts on $G_{\Delta}$, TON concentrations were measured as a surrogate to estimate the total concentration of N-DBPs. Table 1 showed that the N-DBP production in the mixture was lower than the sum of production by the individual precursors. Nevertheless, $\mathrm{G}_{\Delta}$ was greater than 0 for $\mathrm{pH}$ values from 5.0 to 6.1 (Fig. 2), and the above results showed a synergistic effect in the post-chlorination mixture at $\mathrm{pH}$ 5.0-7.0 (Fig. 4). Based on comparison of the TEQ 4 -NQO values from the chlorinated mixture $(11.9 \mu \mathrm{g} / \mathrm{L}$ at $\mathrm{pH} 5.0$ and $6.6 \mu \mathrm{g} / \mathrm{L}$ at $\mathrm{pH} 6.0)$ and the post-chlorination mixture $(9.5 \mu \mathrm{g} / \mathrm{L}$ at $\mathrm{pH} 5.0$ and $6.3 \mu \mathrm{g} / \mathrm{L}$ at $\mathrm{pH}$ 6.0), we concluded that synergistic effects were the main cause for $G_{\Delta}>0$. However, $G_{\Delta}>0$ could not be fully explained by synergistic effects. Differences in the $\mathrm{N}$-DBP composition might also contributed to the occurrence of $G_{\Delta}>0$.

In contrast, $\mathrm{G}_{\Delta}$ was observed to be less than 0 for $\mathrm{pH}$ values from 6.3 to 8.0 (Fig. 2). We found that this was related to a decrease in $\mathrm{N}$-DBPs that were produced from the mixture as compared to the sum of those from the individual chlorinated precursors (Table 1). As $\mathrm{pH}$ increased from 5.0 to 8.0, N-DBPs decreased significantly in the mixture (Table 1), and the synergistic effect decreased, and then an antagonistic effect took place (Fig. 4). The decrease of N-DBPs in 
Table 1

TON concentrations in chlorinated Tyr and BP-4 mixture and in chlorinated individuals and the TON ratio.

\begin{tabular}{|c|c|c|c|c|}
\hline $\mathrm{pH}$ values & {$[\mathrm{Tyr}]_{0}:[\mathrm{BP}-4]_{0}$} & $\mathrm{M}_{\mathrm{TON}}(\mathrm{mg} / \mathrm{L})$ & $\mathrm{I}_{\mathrm{TON}}(\mathrm{mg} / \mathrm{L})$ & TON ratio \\
\hline $\mathrm{pH}=5.0$ & $8: 2$ & $0.856 \pm 0.01$ & $0.944 \pm 0.02$ & $0.911 \pm 0.02$ \\
\hline \multirow[t]{3}{*}{$\mathrm{pH}=6.0$} & $2: 8$ & $0.062 \pm 0.01$ & $0.106 \pm 0.01$ & $0.572 \pm 0.01$ \\
\hline & $5: 5$ & $0.131 \pm 0.02$ & $0.265 \pm 0.01$ & $0.491 \pm 0.02$ \\
\hline & $8: 2$ & $0.274 \pm 0.02$ & $0.424 \pm 0.01$ & $0.637 \pm 0.03$ \\
\hline $\mathrm{pH}=7.0$ & $8: 2$ & $0.135 \pm 0.01$ & $0.408 \pm 0.01$ & $0.331 \pm 0.02$ \\
\hline $\mathrm{pH}=8.0$ & $8: 2$ & $0.050 \pm 0.01$ & $0.232 \pm 0.01$ & $0.216 \pm 0.04$ \\
\hline
\end{tabular}

Note: $\mathrm{M}_{\mathrm{TON}}$ represents the TON concentrations of chlorinated Tyr and BP-4 mixture and $\mathrm{I}_{\mathrm{TON}}$ represents the sum of the TON concentration of chlorinated single precursor.

$\mathrm{I}_{\mathrm{TON}(2: 8)}=0.2 \mathrm{M}_{\mathrm{TON}(1: 0)}+0.8 \mathrm{M}_{\mathrm{TON}(0: 1)}$.

$\mathrm{I}_{\mathrm{TON}(5: 5)}=0.5 \mathrm{M}_{\mathrm{TON}(1: 0)}+0.5 \mathrm{M}_{\mathrm{TON}(0: 1)}$.

$\mathrm{I}_{\mathrm{TON}(8: 2)}=0.8 \mathrm{M}_{\mathrm{TON}(1: 0)}+0.2 \mathrm{M}_{\mathrm{TON}(0: 1)}$.

TON ratio $=\mathrm{M}_{\mathrm{TON}(\mathrm{x}: \mathrm{y})} / \mathrm{I}_{\mathrm{TON}(\mathrm{x}: \mathrm{y})}(\mathrm{x}, \mathrm{y})=(2: 8),(5: 5)$ and $(8: 2) \mathrm{M}_{\mathrm{TON}(0: 1)}=0$.

Error bars represent the standard deviation of replicate measurements $(n=3)$.

the mixture rather than a synergistic effect played a leading role in $\mathrm{G}_{\Delta}$ being less than 0 at high $\mathrm{pH}$. Accordingly, the value of $\mathrm{G}_{\Delta}$ was determined by the combined impacts of synergistic or antagonist effects of the DBPs and the decrease of N-DBPs in the mixture.

\subsection{Estimation of $G_{\Delta}$ by TON ratio}

In this study, the reaction pathway of N-DBPs was consistent in the chlorination of Tyr alone and in mixture. The TON ratio, defined as TON (chlorinated mixture) $/ T O N$ (the sum of chlorinated individuals), was adopted to estimate $G_{\Delta}$ (Table 1 ). A non-linear regression analysis suggested that there was a significant correlation between $\mathrm{G}_{\Delta}$ and TON ratio $\left(\mathrm{R}^{2}=0.997, p<0.01\right)$ (Fig. 5). The regression equation $\left(y=18.5 x^{2}-9.9 x+0.9\right)$ could be used to estimate $G_{\Delta}$.

Remarkably, all TON ratios were lower than 1, indicating the addition of BP-4 decreases the production of N-DBPs from Tyr. On the basis of previous literature, chlorination reactions with Tyr [41] and BP-4 [13] were described by following Eqs. (1) and (2)

$-\mathrm{d}[\mathrm{Tyr}] / \mathrm{dt}=k_{o b s}[\mathrm{Tyr}][$ Chlorine $]$

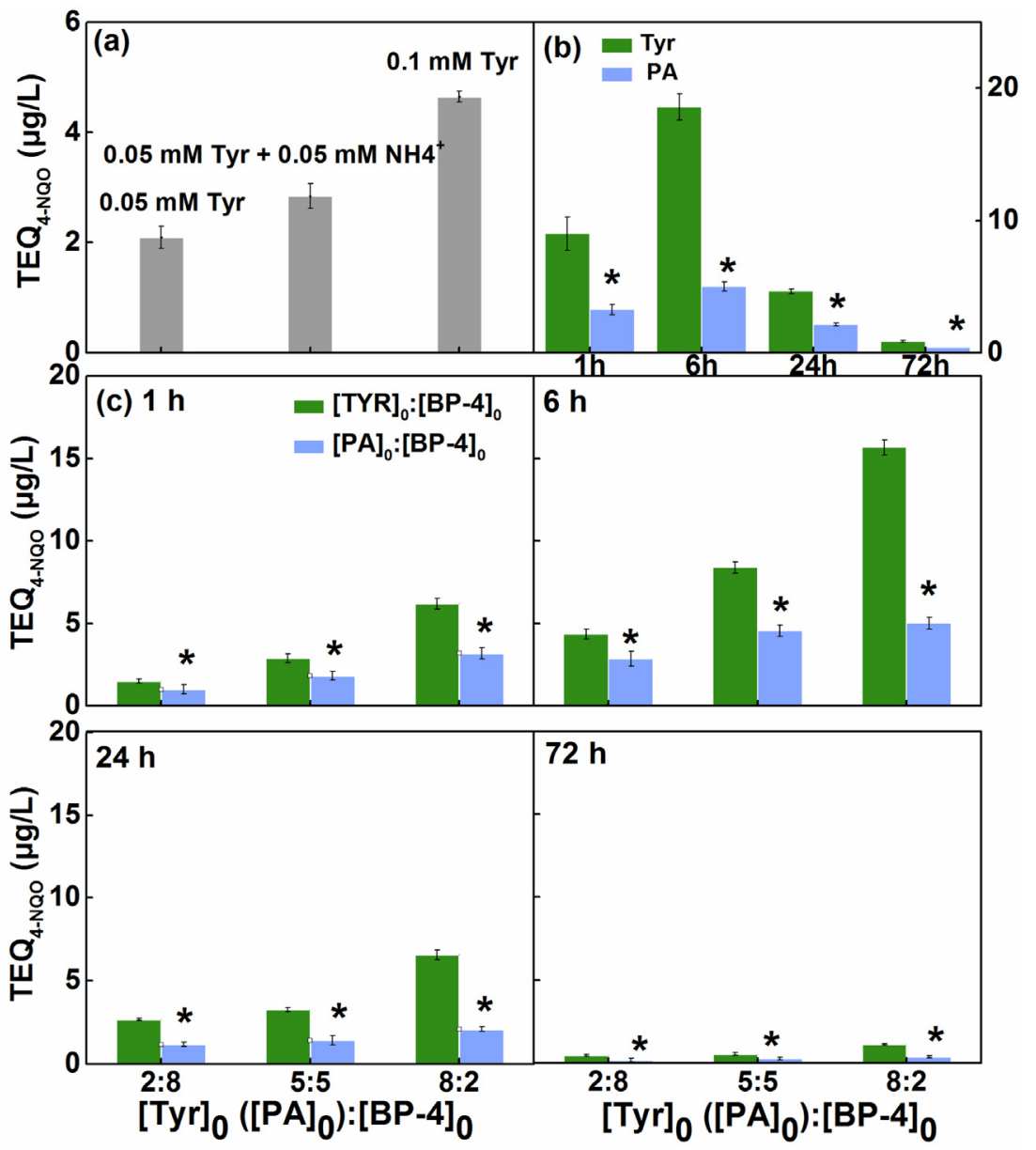

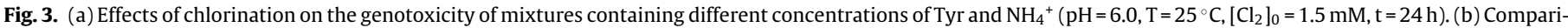

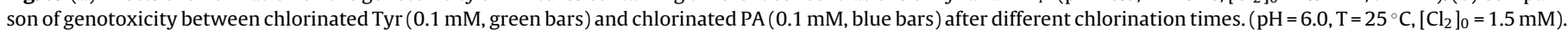

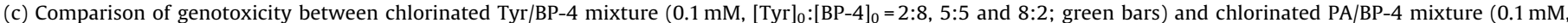

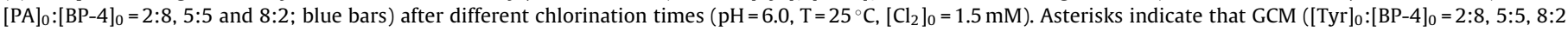

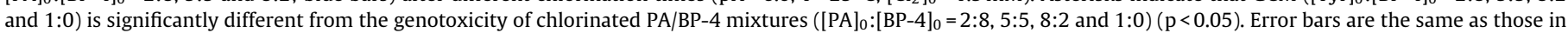
Fig. 1. (For interpretation of the references to colour in this figure legend, the reader is referred to the web version of this article.) 


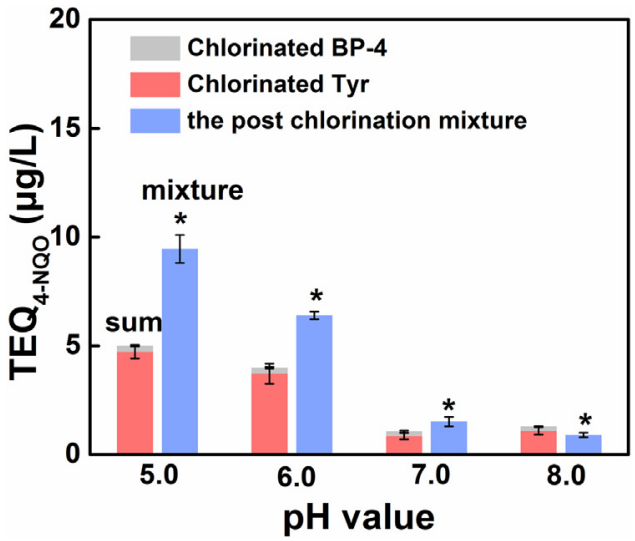

Fig. 4. Comparison of GCI and the genotoxicity of the post-chlorination mixture $\left([\mathrm{Tyr}]_{0}=0.08 \mathrm{mM},[\mathrm{BP}-4]_{0}=0.02 \mathrm{mM}\right)$ at varying $\mathrm{pH}$ values $\left(\mathrm{T}=25^{\circ} \mathrm{C},\left[\mathrm{Cl}_{2}\right]_{0}=1.5 \mathrm{mM}\right.$, $\mathrm{t}=24 \mathrm{~h}$ ). Asterisks indicate that the genotoxicity of the post-chlorination mixture is significantly different from $\mathrm{GCI}(\mathrm{p}<0.05)$. Error bars are the same as those in Fig. 1.

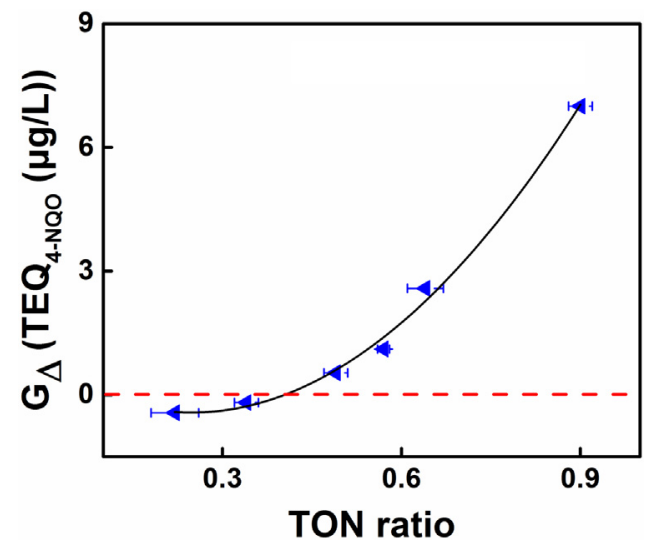

Fig. 5. The non-linear regression analysis of $G_{\Delta}$ at varying $T O N$ ratios $\left(\mathrm{T}=25^{\circ} \mathrm{C}, \quad\left[\mathrm{Cl}_{2}\right]_{0}=1.5 \mathrm{mM}, \quad \mathrm{t}=24 \mathrm{~h}\right)$. TON ratio was defined as $\mathrm{TON}_{\text {(chlorinated mixture) }} / \mathrm{TON}_{(\text {the sum of chlorinated individual) }}$. Error bars are the same as those in Fig. 1.

$-\mathrm{d}[\mathrm{BP}-4] / \mathrm{dt}=k_{o b s}^{\prime}[\mathrm{BP}-4]$

where $k_{o b s}, k_{o b s}^{\prime}$ represent the rate constants of Tyr and BP-4, respectively. $k_{o b s}\left(10^{5}\right)$ was observed to be approximately 3 to 4 orders of magnitude higher than $k^{\prime}{ }_{o b s}\left(10^{1}-10^{2}\right)[39,41]$. Under the same chlorine dosage, compared with Tyr alone, Tyr in mixture could be reacted with more chlorine, thus accelerating the Tyr chlorination. Based on the reaction pathway of Tyr, N-DBPs are generated and then hydrolyzed to form C-DBPs [19]. During the contact time between $6 \mathrm{~h}$ and $72 \mathrm{~h}, \mathrm{~N}$-DBPs were being degraded (Fig. S7). So Tyr in mixture produced less N-DBPs at $24 \mathrm{~h}$ as compared to Tyr alone. To verify the effect of chlorine dosage on the degradation of N-DBPs, the genotoxicity and TON concentrations of Tyr under various chlorine dosages $\left(\left[\mathrm{Cl}_{2}\right]_{0}:[\mathrm{Tyr}]_{0}=7.5: 1,15: 1\right.$ and 30:1) were measured (Fig. 6). The decreases in genotoxicity and TON concentrations were statistically significant $(p<0.01)$ with increasing chlorine dosage. This result suggested that the TON ratio was lower than 1 because the formation of N-DBPs in mixture was lower than with Tyr alone. Moreover, the TON ratio decreased with increasing $\mathrm{pH}$ (Fig. 5). This may be associated with the $\mathrm{pH}$ dependence of $k_{o b s}$ and $k_{o b s}^{\prime}$. It has been proved that a rise in $\mathrm{pH}$ can lead to increases of $k_{o b s}$ and $k_{o b s}^{\prime}[13,42]$, and the increase of $k_{o b s}$ is much larger than that of $k^{\prime}$ obs. More chlorine reacted with Tyr in mixture at higher $\mathrm{pH}$, thus decreasing the TON ratio. As a consequence, the $\mathrm{pH}$ dependence of the rate constant is responsible for the variation in the TON ratio.

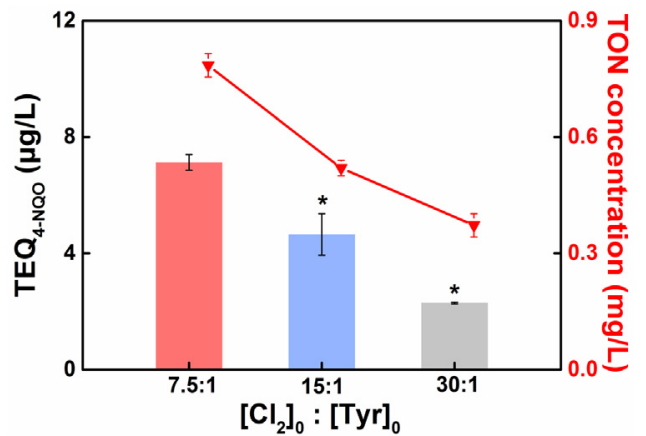

Fig. 6. Genotoxicity and total organic nitrogen (TON) concentrations of chlorinated $\operatorname{Tyr}(0.1 \mathrm{mM})$ with different chlorine dosages $\left(\mathrm{pH}=6.0, \mathrm{~T}=25^{\circ} \mathrm{C}, \mathrm{t}=24 \mathrm{~h}\right)$. Asterisks indicate that the genotoxicity is significantly different for chlorinated Tyr with different chlorine dosages $(p<0.05)$. Error bars are the same as those in Fig. 1.

\section{Conclusions}

This study investigated the role of $\mathrm{pH}$ in controlling $\mathrm{G}_{\Delta}$. We confirmed that the genotoxicity of a chlorinated Tyr and BP-4 mixture could not be estimated from the sum of the genotoxicities of the individual chlorinated precursors. $\mathrm{pH}$ was an important influencing factor affecting $\mathrm{G}_{\Delta} . \mathrm{G}_{\Delta}$ decreased with increasing $\mathrm{pH}$ values from 5.0 to 8.0. $\mathrm{G}_{\Delta}>0$ occurred at $\mathrm{pH} 5.0-6.1$, and $\mathrm{G}_{\Delta}<0$ occurred at $\mathrm{pH}$ 6.3-8.0. Synergistic effects played a crucial role in the genotoxicity of the chlorinated mixture and induced a higher genotoxicity $\left(G_{\Delta}>0\right)$. A reduction of N-DBPs in the mixture caused $G_{\Delta}$ to be less than 0 . Although the precursors in this study were single compounds (Tyr and BP-4), our study provided valuable insight regarding the genotoxicity of DBPs from other multiple precursors. It is expected that researchers will pay more attention to the genotoxicity difference between mixtures and individual precursors after chlorination to correctly evaluate the DBPs' potential negative effects on ecological systems and human health. In addition, the role of the N-DBPs and combined effects during the evaluation of genotoxicity differences is likely to be of particular concern.

\section{Acknowledgements}

This work is supported by the National Natural Science Foundation of China (Nos. 51290282, 51578537 and 51420105012) and the National Water Pollution Control and Treatment Science and Technology Major Project (2014ZX07405003). We thank Prof. Zijian Wang for providing technical support. This research is also supported by the Brook Byers Institute for Sustainable Systems, Hightower Chair, and the Georgia Research Alliance at the Georgia Institute of Technology.

\section{Appendix A. Supplementary data}

Supplementary data associated with this article can be found, in the online version, at http://dx.doi.org/10.1016/j.jhazmat.2016.10. 014.

\section{References}

[1] U.V. Gunten, A. Driedger, H. Gallard, E. Salhi, By-products formation during drinking water disinfection: a tool to assess disinfection efficiency, Water Res. 35 (2001) 2095-2099.

[2] S.D. Richardson, M.J. Plewa, E.D. Wagner, R. Schoeny, D.M. Demarini, Occurrence, genotoxicity, and carcinogenicity of regulated and emerging disinfection by-products in drinking water: a review and roadmap for research, Mutat. Res. Fundam. Mol. Mech. 636 (2007) 178-242.

[3] M. Siddiqui, G. Amy, J. Ryan, W. Odem, Membranes for the control of natural organic matter from surface waters, Water Res. 34 (2000) 3355-3370. 
[4] R. Shen, S.A. Andrews, Demonstration of 20 pharmaceuticals and personal care products (PPCPs) as nitrosamine precursors during chloramine disinfection, Water Res. 45 (2011) 944-952.

[5] A.A. Kampioti, E.G. Stephanou, The impact of bromide on the formation of neutral and acidic disinfection by-products (DBPs) in Mediterranean chlorinated drinking water, Water Res. 36 (2002) 2596-2606.

[6] Y. Bichsel, U.V. Gunten, Formation of iodo-trihalomethanes during disinfection and oxidation of iodide-containing waters, Environ. Sci. Technol. 34 (2000) 2784-2791.

[7] C.M. Villanueva, G. Castaño-Vinyals, V. Moreno, G. Carrasco-Turigas, N. Aragonés, E. Boldo, E. Ardanaz, E. Toledo, J.M. Altzibar, I. Zaldua, Concentrations and correlations of disinfection by-products in municipal drinking water from an exposure assessment perspective, Environ. Res. 114 (2012) 1-11.

[8] G.E. Boven Jr., P.A. Rogerson, J.E. Vena, Case control study of the geographic variability of exposure to disinfectant byproducts and risk for rectal cancer, Int. J. Health Geogr. 6 (2007) 2565-2586.

[9] M.J. Nieuwenhuijsen, J. Grellier, R. Smith, N. Iszatt, J. Bennett, N. Best, M. Toledano, The epidemiology and possible mechanisms of disinfection by-products in drinking water, Philos. Trans. A Math. Phys. Eng. Sci. 367 (2009) 4043-4076.

[10] C.M. Villanueva, M. Kogevinas, Disinfection byproducts and bladder cancer: a pooled analysis, Epidemiology 15 (2004) 357-367.

[11] L. Li, D. Wei, G. Wei, Y. Du, Transformation of cefazolin during chlorination process: products, mechanism and genotoxicity assessment, J. Hazard. Mater 262 (2013) 48-54

[12] J. Owusu-Yaw, W.B. Wheeler, C.I. Wei, Genotoxicity studies of the reaction of chlorine or chlorine dioxide with L-tryptophan, Toxicol. Lett. 56 (1991) 213-227.

[13] M. Xiao, D. Wei, J. Yin, G. Wei, Y. Du, Transformation mechanism of benzophenone-4 in free chlorine promoted chlorination disinfection, Water Res, 47 (2013) 6223-6233.

[14] D. Wang, Z. Xu, Y. Zhao, X. Yan, J. Shi, Change of genotoxicity for raw and finished water: role of purification processes, Chemosphere 83 (2011) 14-20.

[15] B.A. Lyon, R.Y. Milsk, A.B. Deangelo, J.E. Simmons, M.P. Moyer, H.S. Weinberg, Integrated chemical and toxicological investigation of

UV-chlorine/chloramine drinking water treatment, Environ. Sci. Technol. 48 (2014) 6743-6753.

[16] Y. Shi, X.W. Cao, F. Tang, H.R. Du, Y.Z. Wang, X.Q. Qiu, H.P. Yu, B. Lu, In vitro toxicity of surface water disinfected by different sequential treatments, Water Res. 43 (2008) 218-228.

[17] N.M. Ram, A review of the significance and formation of chlorinated $\mathrm{N}$-organic compounds in water supplies including preliminary studies on the chlorination of alanine tryptophan, tyrosine, cytosine, and syringic acid, Environ. Int. 11 (1985) 441-451

[18] L. Szajdak, R. Österberg, Amino acids present in humic acids from soils under different cultivations, Environ. Int. 22 (1996) 331-334.

[19] W.A. Mitch, S.W. Krasner, P. Westerhoff, A. Dotson, Occurrence and Formation of Nitrogenous Disinfection By-Products, American Water Works Association Research Foundation, Denver, Colo, 2009.

[20] W. Chu, N. Gao, S.W. Krasner, M.R. Templeton, D. Yin, Formation of halogenated C-, N-DBPs from chlor(am)ination and UV irradiation of tyrosine in drinking water, Environ. Pollut. 161 (2012) 8-14.

[21] H.C. Hong, M.H. Wong, Y. Liang, Amino acids as precursors of trihalomethane and haloacetic acid formation during chlorination, Arch. Environ. Contam. Toxicol. 56 (2009) 638-645.

[22] M.L. Trehy, R.A. Yost, C.J. Miles, Chlorination byproducts of amino acids in natural waters, Environ. Sci. Technol. 20 (1986) 1117-1122.

[23] W.H. Chu, N.Y. Gao, Y. Deng, S.W. Krasner, Precursors of dichloroacetamide, an emerging nitrogenous DBP formed during chlorination or chloramination, Environ. Sci. Technol. 44 (2010) 3908-3912.
[24] M.S. Díaz-Cruz, M. Llorca, D. Barceló, D. Barceló, Organic UV filters and their photodegradates, metabolites and disinfection by-products in the aquatic environment, TrAC Trend Anal. Chem. 27 (2008) 873-887.

[25] F. Stenback, Local and systemic effects of commonly used cutaneous agents: lifetime studies of 16 compounds in mice and rabbits, Acta Pharmacol. Toxicol. 41 (1977), 41-31.

[26] S. Wahie, J.J. Lloyd, P.M. Farr, Sunscreen ingredients and labelling: a survey of products available in the UK, Clin. Exp. Dermatol. 32 (2007) 359-364.

[27] R. Rodil, J.B. Quintana, P. López-Mahía, S. Muniategui-Lorenzo, D. Prada-Rodríguez, Multiclass determination of sunscreen chemicals in water samples by liquid chromatography-tandem mass spectrometry, Anal. Chem. 80 (2008) 1307-1315.

[28] K. Fent, A. Zenker, M. Rapp, Widespread occurrence of estrogenic UV-filters in aquatic ecosystems in Switzerland, Environ. Pollut. 158 (2010) 1817-1824.

[29] M.G. Muellner, E.D. Wagner, K. Mccalla, S.D. Richardson, Y.T. Woo, M.J. Plewa, Haloacetonitriles vs. regulated haloacetic acids: are nitrogen-containing DBPs more toxic, Environ. Sci. Technol. 41 (2007) 645-651.

[30] M.J. Plewa, M.G. Muellner, S.D. Richardson, F. Fasano, K.M. Buettner, Y.T. Woo, A.B. Mckague, E.D. Wagner, Occurrence, synthesis, and mammalian cell cytotoxicity and genotoxicity of haloacetamides: an emerging class of nitrogenous drinking water disinfection byproducts, Environ. Sci. Technol. 42 (2008) 955-961.

[31] M.J. Plewa, E.D. Wagner, P. Jazwierska, S.D. Richardson, P.H. Chen, A.B. Mckague, Halonitromethane drinking water disinfection byproducts: chemical characterization and mammalian cell cytotoxicity and genotoxicity, Environ. Sci. Technol. 38 (2015) 62-68.

[32] J.L. Burleson, G.R. Peyton, W.H. Glaze,

Gas-chromatographic/mass-spectrometric analysis of derivatized amino acids in municipal wastewater products, Environ. Sci. Technol. 14 (2002) 1354-1359.

[33] USEPA Method 551.1, 1995. J.W. Munch, D.P. Hautman, Determination of chlorination disinfection by-products, chlorinated solvents, and halogenated pesticides/herbicides in drinking water by liquid-liquid ex-traction and gas chromatograph with electron-capture detec-tion (Revision 1.0). Office of Research and Development, Washington, DC.

[34] USEPA Method 552.3, 1995. D.J. Munch, J.W. Munch, A.M. Pawlecki, Determination of haloacetic acids in drinking water by liquid-liquid extraction, derivatization and gas chromatograohy with electron capture detection. Office of Research and Development, Washington, DC.

[35] G.I.O.F. Standardization, Water quality - Determination of Kjeldahl nitrogen Method after mineralization with selenium, International Standard Iso (1984).

[36] National Standards of the People's Republic of China GB7479-87, 1987. Water Quality, Determination of Ammonium by the Nessler's Reagent Colorimetric Method (in Chinese). Ministry of Environmental Protection of the People's Republic of China (MEPPRC): Beijing, China.

[37] Y. Oda, S. Nakamura, I. Oki, T. Kato, H. Shinagawa, Evaluation of the new system (umu-test) for the detection of environmental mutagens and carcinogens, Mutat. Res. Fundam. Mol. Mech. 147 (1985) 219-229.

[38] X. Gao, B. Zhang, G. Zhong, D. Zhang, Combination of in vitro bioassays for the determination of cytotoxic and genotoxic potential of wastewater, surface water and drinking water samples, Chemosphere 75 (2009) 1453-1460.

[39] D. Wei, Z. Tan, Y. Du, Toxicity-based assessment of the treatment performance of wastewater treatment and reclamation processes, J. Environ. Sci. 24 (2012) 969-978.

[40] Y. Xin, Q. Shen, W. Guo, J. Peng, Y. Liang, Precursors and nitrogen origins of trichloronitromethane and dichloroacetonitrile during chlorination/chloramination, Chemosphere 88 (2012) 25-32.

[41] C.N. And, T.M. Olson, Relative reactivity of amino acids with chlorine in mixtures, Environ. Sci. Technol. 41 (2007) 3220-3225.

[42] X.L. Armesto, M.L. Canle, J.A. Santaballa, $\alpha$-Amino acids chlorination in aqueous media, Tetrahedron 49 (1993) 275-284. 